Introduction The organophosphates (OPs) are a group of insecticides that have been widely used worldwide for the past 50 years. It is estimated that 3,000,000 people are exposed to OPs yearly, with the associated death rate being 3,00,000 deaths/year. OPs are cholinergic inhibitors and their toxicity is possible through acute or chronic exposure, with severe consequences for different organs and systems. The main objective of this study was to identify signs and symptoms of exposure to OPs on women with chronic exposure.

Methods A prospective study (1994-2014) followed up 43 women exposed to OPs, and evaluated signs and symptoms described as being associated to OPs exposure, as well as analytical parameters associated to asthenia and cellular protection, namely pyruvate (PA) and lactate (LA).

Results During the first appointment, 98\% of the women had asthenia. Among the evaluated signs and symptoms, musculoskeletal injuries (78\%) and menstrual cycle changes (36\%) occurred with the highest frequency. Slightly less frequent were the changes observed in the peripherical nervous system (11\%). Regarding the evaluated biochemical parameters, women generally showed a decrease in ferritin and an increase in TSH. Throughout the study a progressive drop in AChE was observed. In $64 \%$ and $92 \%$ of the women a change in PA and LA values respectively was observed.

Discussion The results suggest that prolonged exposure to OPs can chronically affect different human organism systems, namely parameters related to mitochondrial dysfunction

\section{DERMAL EXPOSURE TO DIISOCYANATES: DEVELOPMENT AND VALIDATION OF AN ANALYTICAL METHOD FOR ACCURATELY ASSESSMENT OF VERY LOW LEVELS OF EXPOSURE}

${ }^{1}$ Radu-Corneliu Duca* ${ }^{1}$ Matteo Creta, ${ }^{1}$ Katrien Poes, 1,2 lode Goddeis, ${ }^{1} J$ Jeroen Vanoirbeek. 'Environment and Health, Department of Public Health and Primary Care, University of Leuven, Leuven, Belgium; ${ }^{2}$ External Service for Prevention and Protection at Work, IDEWE, Haasrode, Belgium

\subsection{6/oemed-2018-ICOHabstracts. 1185}

Introduction Dermal exposure to sensitizers such as diisocyanate have been described to promote the development of asthma in later stages when respiratory occupational exposure occurs. Therefore, we developed a reliable, sensitive and validated methodology based on dermal patches to assess skin exposure to diisocyanates.

Methods An UPLC-Unispray-MS/MS method was established and validated in order to reach very low levels of detection. Custom-made dermal patches were developed in order to allow optimal sampling of diisocyanates. Their sampling capability was evaluated in a controlled environment test-chamber were patches were exposed to increasing concentrations of diisocyanates.

Result The UPLC-MS/MS method using a Unispray ionisation source, based on supercritical fluids ionisation and Coanda effect, allowed reaching very low levels of detection $(\operatorname{LoD}=1$ $\mathrm{pg} / \mathrm{mL}$ ) for all the targeted compounds (i.e. 4,4-MDI, 2,4MDI, 2,6-TDI, 2,4-TDI, 1,6-HDI, and IPDI). Due to the high sensitivity of the analytical method, very low levels of diisocyanates (i.e. $25 \mathrm{pg} / \mathrm{patch}$ ) are detected on the custom-made dermal patches. Furthermore, the patches allowed the sampling of a broad range of concentration levels (from $5 \mathrm{pg} / \mathrm{cm}^{2}$ to $5 \mathrm{ng} / \mathrm{cm}^{2}$ ), which have been correlated with the air levels from the controlled environment chamber-test.
Discussion We succeeded to develop a method to assess dermal exposure to diisocyanates. Field studies are now necessary to further evaluate the suitability of the custom-made patches, as well as to relate low levels of exposure and potential health outcomes.

\section{Primary Care and Work}

\section{SCALING UP WORKERS' HEALTH COVERAGE THROUGH PRIMARY HEALTH CARE}

${ }^{1}$ Garth Manning, ${ }^{2}$ Frank van Dijk, ${ }^{2}$ Peter Buijs. 'Chief Executive Officer, World Organisation of Family Doctors (WONCA); Bangkok, Thailand; 'Learning and Developing Occupational Health (LDOH) foundation, The Netherlands

\subsection{6/oemed-2018-ICOHabstracts. 1186}

Aim To explore ways of upskilling primary health care to offer essential occupational health to a broader population; some country examples.

Presenters: ${ }^{1}$ Prof Jukka Takala, ${ }^{2}$ Dr Ramnik Parekh, ${ }^{3}$ Dr Orrapan Untimanon, ${ }^{4}$ Dr Hanifa M Denny, ${ }^{5}$ Dr Ezequiel Lopez, ${ }^{6} \mathrm{Dr}$ Muzimkhulu Zungu, ${ }^{7}$ Dr Ahmet Özlüh, ${ }^{8}$ Dr Paul Smits

${ }^{1}$ President of International Commission on Occupational Health (ICOH); Senior Consultant, Ministry of Manpower Services Centre, Singapore

${ }^{2}$ Chair- Mission BOHS: Indian Association of Occupational Health (IAOH), Mumbai, India

${ }^{3}$ Bureau of Occupational and Environmental Diseases, Department of Disease Control, Ministry of Public Health, Thailand

${ }^{4}$ Diponegoro University, Semarang, Indonesia

${ }^{5}$ Clinica Belgrano Family Medicine and Occupational Health Department, Quilmes, Argentina

${ }^{6}$ National Institute for Occupational Health School of Health Systems and Public Health, University of Pretoria

${ }^{7}$ Republic of Turkey Ministry of Health, General Directorate of Public Health, Ankara, Turkey

${ }^{8}$ Centre for evidence-based education, Academic Medical Centre (AMC), Amsterdam, The Netherlands

\section{1a GLOBAL BACKGROUND OF INSUFFICIENT COVERAGE BY OCCUPATIONAL HEALTH SERVICES: WHAT CAN WE DO TO SUPPORT PREVENTION AND CARE}

Jukka Takala. Senior Consultant, Ministry of Manpower Services Centre, Singapore

\subsection{6/oemed-2018-ICOHabstracts. 1187}

Background According to latest estimates by ILO 2.8 million men and women die every year caused by problems at work. Health disorders cause 2.4 million deaths. Costs are $3.9 \%$ of the global GDP or 3 trillion (million millions) USD. Problems include: poor legal and enforcement coverage, poor or no workers' compensation systems, poor or no occupational health services - some $15 \%$ or less of the global workforce is covered. According to WHO 93\% of global health resources go for treatment and 7\% for prevention. Lack of knowledge, policies, systems and resources is evident.

Methods and processes A number of solutions and good practices have been identified to be useful and successful, although largely in developed countries. Simple methods to increase coverages and enhance services are needed. The ILO 